\title{
The effect of vitamin D supplementation on the glycemic control of pre-diabetic Qatari patients in a randomized control trial
}

\author{
Mohammed Al Thani ${ }^{1}$, Eman Sadoun², Angeliki Sofroniou', Amin Jayyousi ${ }^{3}$, Khaled Ahmed Mohamed Baagar ${ }^{3}$, \\ Abdulla Al Hammaq ${ }^{4}$, Benjamin Vinodson ${ }^{1}$, Hammad Akram¹, Zaid Shakoor Bhatti ${ }^{2}$, Heba Samir Nasser ${ }^{1}$ and \\ Vasiliki Leventakou ${ }^{2^{*}}$
}

\begin{abstract}
Background: Vitamin D deficiency is associated with indicators of pre-diabetes including, insulin resistance, $\beta$-cell dysfunction and elevated plasma glucose with controversial findings from current trials. This study aims to investigate the long-term effect of vitamin D on glucose metabolism and insulin sensitivity in pre-diabetic and highly vitamindeficient subjects.
\end{abstract}

Methods: One hundred thirty-two participants were randomized to 30,000 IU vitamin D weekly for 6 months. Participants underwent oral glucose tolerance test (OGTT) at 3-month intervals to determine the change in plasma glucose concentration at $2 \mathrm{~h}$ after $75 \mathrm{~g}$ OGT (2hPCG). Secondary measurements included glycated hemoglobin, fasting plasma glucose and insulin, post-prandial insulin, indices of insulin sensitivity (HOMA-IR, Matsuda Index), $\beta$-cell function (HOMA- $\beta$, glucose and insulin area under the curve (AUC), disposition and insulinogenic indices), and lipid profile.

Results: A total of 57 (vitamin D) and 75 (placebo) subjects completed the study. Mean baseline serum 25(OH) D levels were $17.0 \mathrm{ng} / \mathrm{ml}$ and $14.9 \mathrm{ng} / \mathrm{ml}$ for placebo and vitamin D group, respectively. No significant differences were observed for $2 \mathrm{hPC}$ glucose or insulin sensitivity indices between groups. HOMA- $\beta$ significantly decreased in the vitamin D group, while area under curve for glucose and insulin showed a significant reduction in $\beta$-cell function in both groups. Additionally, HOMA- $\beta$ was found to be significantly different between control and treatment group and significance persisted after adjusting for confounding factors.

Conclusion: Vitamin D supplementation in a pre-diabetic and severely vitamin-deficient population had no effect on glucose tolerance or insulin sensitivity. The observed reduction in $\beta$-cell function in both placebo and vitamin D groups could be attributed to factors other than supplementation.

Trial registration: NCT02098980, 28/03/2014 (www.clinicaltrials.gov).

Keywords: Vitamin D, Pre-diabetes, $\beta$-Cell function, Glucose metabolism, Middle East

\footnotetext{
* Correspondence: vleventakou@moph.gov.qa

${ }^{2}$ Biomedical Research Department, Ministry of Public Health, P.O. Box 42, Al

Khaleej Str, Al Rumaila, Doha, Qatar

Full list of author information is available at the end of the article
}

(c) The Author(s). 2019 Open Access This article is distributed under the terms of the Creative Commons Attribution 4.0 International License (http://creativecommons.org/licenses/by/4.0/), which permits unrestricted use, distribution, and reproduction in any medium, provided you give appropriate credit to the original author(s) and the source, provide a link to the Creative Commons license, and indicate if changes were made. The Creative Commons Public Domain Dedication waiver (http://creativecommons.org/publicdomain/zero/1.0/) applies to the data made available in this article, unless otherwise stated. 


\section{Background}

Low levels of vitamin D has been identified as a major health issue globally. Current literature provides evidence for the association of hypovitaminosis $\mathrm{D}$ with various health conditions including bone health [1], cardiovascular disease [2], hypertension [3], cancer risk [4] and diabetes mellitus [5]. In particular, higher prevalence of low serum vitamin D [25-(OH)D] levels has been observed among type 2 diabetic patients [6] while higher levels of vitamin $\mathrm{D}[25-(\mathrm{OH}) \mathrm{D}]$ has been associated with lower risk of type 2 diabetes (T2DM) [7, 8]. The increasing rates of diabetes worldwide with diabetic patients reaching 400 million people, a number predicted to exceed 600 million by 2040, can justify the rapid shift of research interest towards prevention and treatment strategies for diabetes, including intervention with vitamin D [9].

Several possible mechanisms have been proposed to mediate the protective role of vitamin $\mathrm{D}$ against diabetes risk including alterations in the pancreatic $\beta$-cell function [10], insulin sensitivity [11] and systemic inflammation [12]. Despite the promising results from observational studies, intervention studies are more appropriate to provide insight on causality and develop hypothesis. Up to date, a number of randomized control trials (RCTs) have been conducted to evaluate the role of vitamin D supplementation in the pathogenesis of type 2 diabetes but results remain inconclusive. Recent systematic reviews and meta-analyses of clinical trials have found no association between vitamin $\mathrm{D}$ and glycemic indices and insulin resistance in patients with $\mathrm{T} 2 \mathrm{DM}$ apart from a modest reduction on fasting glucose in some cases [13-15]. On the contrary, other have reported a small but positive effect of vitamin D supplementation on glycemic control, insulin resistance and glucose tolerance $[5,16,17]$. Regarding the role of vitamin $\mathrm{D}$ in the progression of T2DM definite conclusions cannot also be drawn. There are only few vitamin D intervention studies including pre-diabetic participants with inconsistent observations [18-20]. The disparity in the reported results could be attributed to various types (pills, drops, and vitamin D fortified foods) and doses of vitamin D supplements, participants' vitamin D status (deficient/insufficient), other comorbid conditions, small study samples and possibly restricted time frame of supplementation.

Given the novel research focus on this topic and the conflicting evidence, we sought to expand current literature by including participants highly affected by the risk of developing diabetes [9] and at the same time deficient in vitamin D. These characteristics are likely to alter the efficacy of vitamin D supplementation, since better effects of supplementation have been observed in deficient patients rather than insufficient or sufficient [21]. This is the first placebo-control trial in the Middle East in a population with that aims to investigate the effect of
6 months vitamin D supplementation in pre-diabetic, vitamin-deficient subjects on glucose tolerance, insulin sensitivity and $\beta$-cell function in a relatively large sample.

\section{Methods}

\section{Participants and study design}

This intervention study was a 6-month, double-blind, randomized, placebo-controlled trial conducted at Hamad Medical Corporation (HMC) in Doha, Qatar. The research ethics board of HMC approved the protocol and the trial was registered at www.clinicaltrials.gov (no. NCT02098980). An informed consent was obtained from all participants at enrollment.

Men and women aged 18-75 of multicultural backgrounds were recruited via telephone calls and campaigns held at Qatar landmarks. A two-step process was used to screen for eligibility as shown in Fig. 1. In the first step, screening 1, eligibility was based on a finger prick HbA1c result (5.6-6.4\%) indicating pre-diabetes [22]. During the second screening (visit 0), eligibility was based on physical and biochemical measurements, which included medical history, prescribed medication, height, weight, waist circumference, BMI, pulse, fasting glucose, HbA1c, cholesterol, triglycerides, liver function, blood analyses, insulin, C-peptide, serum $25(\mathrm{OH})$ vitamin $\mathrm{D}_{3}$, parathyroid hormone $(\mathrm{PTH})$ and calcium.

Inclusion criteria were as follows: non-pregnant or lactating women, BMI $<40 \mathrm{~kg} / \mathrm{m}^{2}$, serum $25(\mathrm{OH})$ vitamin D3 concentration $<30 \mathrm{ng} / \mathrm{ml}$, fasting serum glucose $<7.0 \mathrm{mmol} / \mathrm{L}$, HbA1c 5.6-6.4\%. Subject inclusion also relied on the presence of one or more of the following: waist circumference of $>80 \mathrm{~cm}$ for females and $>90 \mathrm{~cm}$ for males [23], older than 40 years old, family history of diabetes in first-degree relative, previous history of gestational diabetes, history of high blood glucose or triglycerides and/or low HDL cholesterol. Participants were excluded if: fasting serum glucose $\geq 7.0 \mathrm{mmol} / \mathrm{L}$, had history of renal failure or liver disease, serum urea or creatinine $>1.8$ times the upper limit of normal (ULN), serum aspartate or alanine transaminase (AST, ALT) > 1.5 times ULN, use of medicine to treat diabetes or which influenced glucose metabolism at the time of screening, experienced a medical or surgical event requiring hospitalization within 3 months of randomization, and if they suffered from any condition affecting nutrient absorption (e.g. irritable bowel syndrome).

At visit 1, study participants were randomly assigned either the placebo or the vitamin $\mathrm{D}$ treatment at a dose of $30,000 \mathrm{IU} /$ week (equivalent to $4000 \mathrm{IU}$ per day) and were given supplements to cover a 3-month period. In this visit they completed the Finnish Diabetes Risk Score (FINDRISC) questionnaire [24], a 24-h recall food questionnaire, signed the consent form, and underwent their 


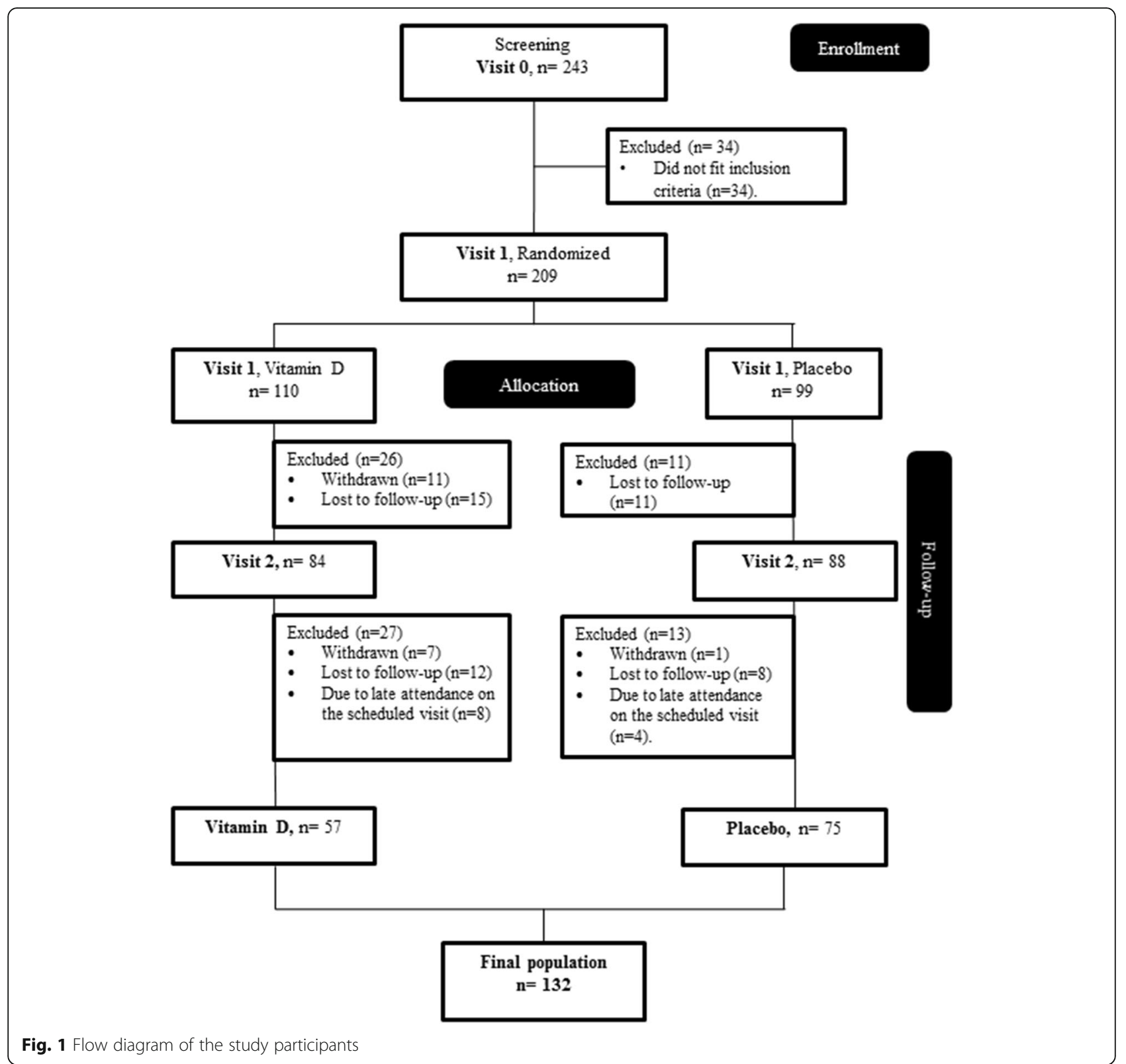

baseline $75 \mathrm{~g}$ OGTT (after overnight fast). All active participants visited the recruitment center two more times in 3-month intervals to complete 6 months of treatment and underwent the same physical and biochemical measurements as in visit 0 and 1 .

\section{Randomization}

ID numbers were assigned to subjects sequentially in the order in which their eligibility was ascertained and informed consent obtained. Subjects were randomly assigned to one of the 2 treatments in blocks of varying sizes. To achieve this, a set of sealed, opaque envelopes labelled with the ID number and containing the preassigned treatment code were created and assigned to subjects in the order they attended for visit 1 . Subjects were randomized to control or vitamin D group opening the next available envelope. Randomization (done using the “@RAND” function on a Lotus 123 spreadsheet) and creation of the sealed envelopes was done by the research team at the recruiting center and a list of ID numbers and coded treatment assignments were kept in a secure web-based database.

\section{Biochemical measurements}

The primary outcome was to determine the change in 2hPCG from baseline to end-point following supplementation with vitamin D. Participants underwent an oral glucose tolerance test (OGTT) at two 3-month intervals 
to determine the change in plasma glucose concentration at $2 \mathrm{~h}$ after $75 \mathrm{~g}$ OGTT (2hPCG). At each OGTT, plasma glucose was measured at four different time points, 30, 60, 90 and 120 min after glucose load. Secondary outcomes included lipid profile, glycated hemoglobin, fasting plasma glucose and insulin, post-prandial insulin, and insulin sensitivity derived from the Homeostatic Model of Assessment - Insulin Resistance (HOMA-IR) and Matsuda Index. B-cell function was measured by HOMA- $\beta$, disposition index (DI), insulinogenic index, and glucose and insulin area under the curve (AUC) from 0 to 120 min during OGTT at each time point (Baseline, 3 months, 6 months).

Serum glucose was measured using the hexokinase/G6-PDH method (Abbott architect $\mathrm{C}$ systems analyzer). Chemiluminescence immunoassay (CLIA) technology (LIAISON Analyzer family) was used for the in vitro quantitative determination of insulin in human serum. Serum $25(\mathrm{OH})$ D were measured by the method of onestep immunoassay using Chemiluminescent Micro Particle Immunoassay (CMIA) technology (Abbott Architect iSystem analyzer).

\section{Statistical analysis}

Data are presented as frequency $(\mathrm{n}, \%)$ and means $( \pm$ standard deviation, SD) and median (interquartile range, IQR) where appropriate. Paired t-test was used to test the within groups differences. For the non-parametric variables, we used the Wilcoxon signed rank test. Unpaired $t$-test was used to compare between two means of parametric continuous variables. Mann-Whitney U test was used to compare between two means of all nonparametric continuous variables. Primary outcomes were analyzed with ANCOVA using a general linear model with the change from baseline to endpoint for each outcome in both placebo and vitamin D groups adjusting for age, gender, baseline BMI and ethnicity. Bivariate associations were tested with Spearman rank correlation test to examine the strength of association between the differences (endpoint and baseline) of vitamin D. Multivariable linear regression models were implemented to test the association between primary and secondary outcomes and vitamin D difference between baseline and endpoint, after adjusting for the aforementioned confounding factors. Estimated associations were described with $\beta$-coefficients and 95\% CI and $R^{2} \mathrm{~A} p$-value $<0.05$ was considered statistically significant. All statistical analyses were performed using SPSS Statistics 19 software (SPSS Inc., Chicago, IL, USA).

Assessment of insulin sensitivity and $\beta$-cell function were estimated by the Homeostasis Model of AssessmentInsulin Resistance Index (HOMA-IR), the Homeostatic Model of Assessment- Beta (HOMA- $\beta$ ) and the Matsuda index and were calculated as follow $[25,26]$ :

$$
\begin{aligned}
& \text { HOMA-IR }=\frac{(\text { Fasting glucose } \times \text { Fasting Insulin })}{22.5} \\
& \text { HOMA- } \% \beta=\frac{20 \times \text { Fasting Insulin }}{\text { Fasting Glucose }-3.5} \\
& \text { The Matsuda Index }=\frac{10,000}{\sqrt{\begin{array}{l}
(\text { Fasting glucose } \times \text { Fasting Insulin } \\
\times(\text { Mean glucose } \times \text { Mean Insulin })
\end{array}}}
\end{aligned}
$$

Additional calculations for $\beta$-cell function include the insulinogenic index and oral disposition index (DI). Insulinogenic index was calculated as the change in insulin divided by change in glucose from 0 to $30 \mathrm{~min}$. Oral disposition index was calculated as the product of (1/fasting insulin) $x$ Insulinogenic index. The area under curve (AUC) for plasma glucose and serum insulin was calculated with the use of the trapezoidal rule method 0120 min (OGTT measurements) for each time point (baseline, 3 months and 6 months). Data were analyzed with repeated measures of ANOVA (no adjustment or interaction was used for this model).

\section{Results}

The participant flow diagram is presented in Fig. 1. A total of 884 were eligible for recruitment based on their HbA1c levels (between 5.6-6.4\%) that indicate prediabetic phase and FINDRISC score (15-30 points) that indicates high to very high risk for T2DM. These participants were invited to the recruitment clinic at HMC, of whom 243 attended the visit. Following further screening of inclusion criteria, 209 participants were randomized to receive either vitamin $\mathrm{D}(n=110)$ or placebo $(n=99)$ treatment. One hundred thirty-two participants successfully completed the trial, of which 57 constituted the vitamin D group and 75 the placebo group.

The baseline participant demographic characteristics were similar in both groups as shown in Table 1 apart from ethnicity. The vitamin D group included $40.4 \%$ participants of Arab ethnicity, whereas $64 \%$ were included in the placebo group. Participants were mainly male, 84 and $82.5 \%$, with mean age 44.89 years (SD 8.88) and 45.51 years (SD 8.96) in the placebo group and vitamin D group, respectively. All participants were vitamin D deficient $(<$ $30 \mathrm{ng} / \mathrm{ml}$ ) with $87 \%$ having $25(\mathrm{OH}) \mathrm{D}$ serum levels below $20 \mathrm{ng} / \mathrm{ml}$ in the vitamin D group.

Clinical characteristics were similar in the two groups (Table 2). HbA1c was $5.9 \%$ (SD 0.22) for the placebo and $5.9 \%$ (SD 0.19) for the vitamin D group. Participants were in the obese range in both groups with mean BMI $32.0 \mathrm{~kg} / \mathrm{m}^{2}$ (SD 5.9) for the placebo and $30.0 \mathrm{~kg} / \mathrm{m}^{2}$ (SD 6.2) for the vitamin $D$ group. Serum $25(\mathrm{OH})$ D levels were slightly reduced in the placebo $(-0.88 \mathrm{ng} / \mathrm{ml}[95 \%$ CI: $-2.2,0.44])$ but almost doubled in the vitamin D group $(19.4 \mathrm{ng} / \mathrm{ml}$ [95\% CI: 16.4, 22.5], $P<0.001)$. 
Table 1 Baseline participant's characteristics

\begin{tabular}{|c|c|c|c|}
\hline & Placebo $(n=75)$ & Vitamin $\mathrm{D}(n=57)$ & $\begin{array}{l}P \text {-value between } \\
\text { groups }\end{array}$ \\
\hline Age (years), mean $\pm S D$ & $44.89 \pm 8.88$ & $45.51 \pm 8.96$ & 0.69 \\
\hline Gender (male), $n$ (\%) & $63(84.0)$ & $47(82.5)$ & 0.81 \\
\hline Ethnicity (Arab), n (\%) & $48(64.0)$ & $23(40.4)$ & 0.007 \\
\hline $25(\mathrm{OH}) \mathrm{D}(<20 \mathrm{ng} / \mathrm{ml}), n$ (\%) & $55(73.3)$ & $45(83.3)$ & 0.18 \\
\hline Family history of diabetes (yes), $n(\%)$ & $52(69.3)$ & $44(77.2)$ & 0.31 \\
\hline Family history of IHD (yes), $n$ (\%) & $15(20.3)$ & $13(23.2)$ & 0.68 \\
\hline Family history of HTN (yes), $n$ (\%) & $43(58.1)$ & $31(55.4)$ & 0.75 \\
\hline $\begin{array}{l}\text { Physically active for at least } 30 \text { min per } \\
\text { day (yes), } n(\%)\end{array}$ & $29(38.7)$ & $21(37.5)$ & 0.89 \\
\hline High blood glucose history (yes), n (\%) & $9(12.0)$ & $6(10.5)$ & 0.79 \\
\hline FINDRISC score, mean \pm SD & $12.01 \pm 4.00$ & $11.96 \pm 4.05$ & 0.94 \\
\hline
\end{tabular}

FINDRISC score: A score calculated based on a questionnaire assessing the risk for diabetes

Abbreviations: IHD Ischemic heart disease, HTN Hypertension, FINDRISC Finnish diabetes risk score

Measures of insulin sensitivity, with respect to the primary outcomes, did not differ between the placebo and vitamin $\mathrm{D}$ groups following the intervention, as presented in Table 2. Within both groups, the 2hPCG was significantly increased $(1.15 \mathrm{mmol} / \mathrm{L}$ [95\% CI: $0.44,1.9]$, $P=0.002$ for vitamin D and $1.09 \mathrm{mmol} / \mathrm{L}$ [95\% CI: 0.44 , 1.7], $P=0.001$ for placebo). With regard to the secondary outcomes, also presented in Table 2, fasting plasma insulin (mean FPI) was decreased in the vitamin D group $(-1.4 \mu \mathrm{U} / \mathrm{ml}$ [95\% CI: $-2.6,-0.19], P=0.024)$ but measures did not differ in group comparison $(P=0.11)$. For the $\beta$-cell function, a significant change was observed for HOMA- $\beta$ between the two groups $(-18.6$ [95\% CI: $30.4,-6.8$ ] vs -0.38 [95\% CI: $-11.7,11.0], P=0.027$ ) and significance persisted after adjusting for age, baseline BMI and gender $(P=0.010)$. HOMA- $\beta$ significantly decreased within the vitamin $\mathrm{D}$ group $(P=0.003)$. Similarly, a slight decrease in insulinogenic index was observed for the same group $(P=0.018)$. An expected but not significant reduction of parathyroid hormone (PTH) was found in the vitamin D group (Table 2). In the same group, serum calcium slightly increased $(0.70$ $\mathrm{mmol} / \mathrm{L}$ [95\% CI: $0.06,1.3], P=0.03)$ and total cholesterol decreased $(-0.32 \mu \mathrm{g} / \mathrm{ml}$ [95\% CI: $-0.58,-0.06$ ], $P=0.02)$ but both measures did not differ between the two groups. Both the systolic $(P<0.001)$ and diastolic pressure $(P=0.004)$ decreased within the treatment group but only diastolic pressure was significant in group comparison $(P=0.036)$. Statistical differences between the vitamin $\mathrm{D}$ and placebo group were also observed for alkaline phosphatase (ALP) $(-6.1 \mathrm{U} / \mathrm{L}$ [95\% CI: $10.1,-2.0]$ vs $3.4[95 \% \mathrm{CI}:-0.24,7.0], P=0.001)$ and bilirubin $(-1.85 \mathrm{umol} / \mathrm{L}[\mathrm{IQR}-5.2,1.2]$ vs -0.75 [IQR -2.4, 2.0], $P=0.039$ ).

As shown in Fig. 2, the AUC for glucose significantly increased within both groups $(P=0.0146, P<0.001)$ from baseline to endpoint (6 months). The opposite was observed for the AUC for insulin $(P<0.001)$ from baseline to endpoint. Significance persisted for both aforementioned measures in group comparison (Additional file 1: Table S1).

In additional bivariate association analysis no significant correlations were found between vitamin D change and clinical characteristics from baseline to 6 months intervention (Additional file 2: Table S2). Multivariable linear regression analyses indicated no significant associations between primary and secondary outcomes and vitamin $\mathrm{D}$ change from baseline to endpoint (data not shown).

\section{Discussion}

Findings from our study showed that vitamin D supplementation over a 6-month period with 30,000 IU vitamin D per week markedly increased $25(\mathrm{OH})$ D levels in the intervention group. Supplementation had no effect on glucose tolerance or insulin sensitivity in our pre-diabetic and severely vitamin-deficient population. Although we observed an impaired $\beta$-cell function suggested by the significant reduction in HOMA- $\beta$ within the vitamin $D$ group and in group comparison, further analysis did not support this observation. The Insulinogenic and Disposition Indices were not significantly different between the two groups. In addition AUC for glucose and insulin was found to be significant within both groups as well as group comparison. Thus, It is unclear whether the changes in $\beta$ cell function can solely be attributed to vitamin $D$ supplementation.

Although heterogeneity across the studies, particularly in the study population characteristics (e.g. sample size, vitamin D status, stage of diabetes) may confound comparison, our findings seem to be in accordance with most available intervention studies. Moreira-Lucas et al. 
Table 2 Baseline values and mean changes for primary and secondary characteristics following 6-month vitamin D intervention

\begin{tabular}{|c|c|c|c|c|c|c|c|c|}
\hline & \multicolumn{3}{|l|}{ Placebo $\left(n=75^{\mathrm{a}}\right)$} & \multicolumn{3}{|l|}{ Vitamin $\mathrm{D}\left(n=57^{\mathrm{a}}\right)$} & \multirow{2}{*}{$\begin{array}{l}P \text {-value } \\
\text { between } \\
\text { groups }\end{array}$} & \multirow{2}{*}{$\begin{array}{l}\text { Adjusted } \\
P \text {-value } \\
\text { between } \\
\text { groups }^{\#}\end{array}$} \\
\hline & Baseline $^{b}$ & Change $^{d}$ & $\begin{array}{l}p \text {-value } \\
\text { within } \\
\text { group" }\end{array}$ & Baseline $^{b}$ & Change $^{d}$ & $\begin{array}{l}P \text {-value } \\
\text { within } \\
\text { group" }\end{array}$ & & \\
\hline Weight (kg) & $91.3 \pm 18.9$ & $-0.57(-1.53,0.39)$ & 0.24 & $86.3 \pm 19.6$ & $0.16(-0.73,1.06)$ & 0.71 & 0.28 & - \\
\hline BMI $\left(\mathrm{kg} / \mathrm{m}^{2}\right)$ & $32.0 \pm 5.9$ & $-0.19(-0.51,0.13)$ & 0.24 & $30.0 \pm 6.2$ & $0.05(-0.25,0.35)$ & 0.75 & 0.30 & - \\
\hline $\begin{array}{l}\text { Waist Circumference } \\
(\mathrm{cm})\end{array}$ & $103.8 \pm 12.6$ & $-0.16(-1.08,0.76)$ & 0.73 & $101.5 \pm 11.0$ & $-0.39(-1.25,0.47)$ & 0.37 & 0.73 & - \\
\hline $\mathrm{HbA} 1 \mathrm{c}(\%)$ & $5.9 \pm 0.22$ & $0.007(-0.10,0.11)$ & 0.90 & $5.9 \pm 0.19$ & $-0.04(-0.12,0.05)$ & 0.37 & 0.54 & - \\
\hline $\mathrm{HbA1c}(\mathrm{mmol} / \mathrm{mol})$ & $41.3 \pm 2.37$ & $0.075(-1.07,1.22)$ & 0.90 & $40.9 \pm 2.02$ & $-0.40(-1.31,0.50)$ & 0.37 & 0.54 & - \\
\hline $\mathrm{SBP}(\mathrm{mmHg})$ & $129.3 \pm 15.5$ & $-5.04(-8.27,-1.81)$ & 0.003 & $127.4 \pm 12.8$ & $-6.59(-10.44,-2.74)$ & 0.001 & 0.54 & - \\
\hline $\mathrm{DBP}(\mathrm{mmHg})$ & $76.6 \pm 12.0$ & $-0.84(-3.08,1.40)$ & 0.46 & $75.9 \pm 9.9$ & $-4.87(-8.10,-1.64)$ & 0.004 & 0.036 & - \\
\hline $\mathrm{RBC}\left(\times 10^{6} \mathrm{uL}\right)$ & $5.2 \pm 0.51$ & $-0.08(-0.15,-0.007)$ & 0.03 & $5.2 \pm 0.58$ & $-0.09(-0.19,0.008)$ & 0.07 & 0.84 & - \\
\hline Hemoglobin (g/dL) & $14.5 \pm 1.4$ & $-0.17(-0.34,-0.004)$ & 0.045 & $14.4 \pm 1.4$ & $0.16(-0.89,1.22)$ & 0.76 & 0.49 & - \\
\hline Hematocrit (\%) & $44.0(42.0,45.7)^{c}$ & $0.0(-1.4,1.6)$ & 0.46 & $43.2(41.4,45.8)$ & $-1.0(-2.4,1.4)$ & 0.15 & 0.07 & - \\
\hline $\begin{array}{l}\text { Total Cholesterol } \\
(\mathrm{mmol} / \mathrm{L})\end{array}$ & $5.1 \pm 0.95$ & $-0.08(-0.25,0.09)$ & 0.37 & $5.3 \pm 0.86$ & $-0.32(-0.58,-0.06)$ & 0.02 & 0.11 & - \\
\hline $\mathrm{HDL}(\mathrm{mmol} / \mathrm{L})$ & $1.1 \pm 0.23$ & $-0.04(-0.07,-0.01)$ & 0.005 & $1.1 \pm 0.26$ & $0.03(-0.08,0.14)$ & 0.58 & 0.15 & - \\
\hline $\mathrm{LDL}(\mathrm{mmol} / \mathrm{L})$ & $3.4 \pm 0.86$ & $-0.08(-0.29,0.12)$ & 0.42 & $3.4 \pm 0.80$ & $-0.15(-0.37,0.06)$ & 0.16 & 0.65 & - \\
\hline Triglyceride (mmol/L) & $1.5 \pm 0.74$ & $0.16(-0.10,0.43)$ & 0.23 & $1.6 \pm 0.84$ & $0.16(-0.31,0.63)$ & 0.49 & 0.99 & - \\
\hline $25(\mathrm{OH}) \mathrm{D}(\mathrm{ng} / \mathrm{ml})$ & $17.0 \pm 4.6$ & $-0.88(-2.20,0.44)$ & 0.19 & $14.9 \pm 4.3$ & $19.4(16.4,22.5)$ & $<0.001$ & $<0.001$ & - \\
\hline PTH $(p g / m l)$ & $57.4 \pm 28.3$ & $7.7(-0.56,15.9)$ & 0.07 & $58.2 \pm 19.4$ & $-3.1(-9.4,3.1)$ & 0.32 & 0.045 & - \\
\hline $\begin{array}{l}\text { Serum Calcium } \\
(\mathrm{mmol} / \mathrm{L})\end{array}$ & $2.25 \pm 1.1$ & $0.51(-0.16,1.2)$ & 0.13 & $1.99 \pm 1.3$ & $0.70(0.06,1.3)$ & 0.03 & 0.67 & - \\
\hline Creatinine (Umol/L) & $74.2 \pm 11.3$ & $-4.1(-7.1,-1.1)$ & 0.008 & $73.0 \pm 17.1$ & $0.53(-4.6,5.7)$ & 0.84 & 0.11 & - \\
\hline CPK (U/L) & $118.5(83.5,201.0)^{c}$ & $-4.5(-32.8,14.2)$ & 0.36 & $124.5(83.7,185.7)$ & $-2.0(-18.0,15.0)$ & 0.55 & 0.79 & - \\
\hline C-peptide (U/L) & $2.1(1.7,3.1)^{c}$ & $0.18(-0.13,0.59)$ & 0.007 & $2.4(1.9,3.1)$ & $0.15(-0.29,0.71)$ & 0.12 & 0.84 & - \\
\hline SGOT (U/L) & $21.0(18.3,26.8)^{c}$ & $-2.0(-7.0,1.0)$ & 0.011 & $22.0(17.8,27.3)$ & $-3.0(-5.0,2.0)$ & 0.062 & 0.88 & - \\
\hline SGPT (U/L) & $26.0(19.0,36.8)^{c}$ & $-3.0(-9.0,1.0)$ & $<0.001$ & $29.0(19.0,42.0)$ & $-3.0(-12.0,3.0)$ & 0.018 & 0.88 & - \\
\hline $\mathrm{ALP}(\mathrm{U} / \mathrm{L})$ & $73.7 \pm 19.6$ & $3.4(-0.24,7.0)$ & 0.07 & $73.8 \pm 17.7$ & $-6.1(-10.1,-2.0)$ & 0.004 & 0.001 & - \\
\hline Bilirubin (umol/L) & $9.05(7.2,14.0)^{c}$ & $-0.75(-2.4,2.0)$ & 0.699 & $11.3(9.7,15.0)$ & $-1.85(-5.2,1.2)$ & 0.006 & 0.039 & - \\
\hline Mean FPG (mmol/L) & $6.3 \pm 0.73$ & $0.13(-0.08,0.35)$ & 0.22 & $6.1 \pm 0.63$ & $0.30(-0.09,0.68)$ & 0.13 & 0.41 & 0.434 \\
\hline $2 \mathrm{~h} \mathrm{PCG}(\mathrm{mmol} / \mathrm{L})$ & $9.3 \pm 2.9$ & $1.09(0.44,1.7)$ & 0.001 & $9.2 \pm 2.4$ & $1.15(0.44,1.9)$ & 0.002 & 0.90 & 0.768 \\
\hline Mean FPI $(\mu \mathrm{U} / \mathrm{ml})$ & $9.8 \pm 6.1$ & $0.64(-1.4,2.7)$ & 0.54 & $9.8 \pm 5.0$ & $-1.4(-2.6,-0.19)$ & 0.024 & 0.11 & 0.137 \\
\hline $2 \mathrm{~h} \mathrm{PCl}(\mu \mathrm{U} / \mathrm{mL})$ & $64.9(38.5,138.3)^{c}$ & $1.2(-30.0,19.2)$ & 0.717 & $98.6(70.1,180.3)$ & $-23.3(-70.9,14.2)$ & 0.06 & 0.22 & 0.882 \\
\hline Matsuda Index & $2.9(1.7,4.1)^{c}$ & $0.21(-0.84,0.95)$ & 0.731 & $2.2(1.7,3.4)$ & $0.08(-0.54,0.99)$ & 0.455 & 0.82 & 0.750 \\
\hline HOMA-IR & $2.5(1.7,3.7)^{c}$ & $0.06(-0.77,0.86)$ & 0.746 & $2.4(1.5,3.4)$ & $-0.05(-0.94,0.44)$ & 0.455 & 0.45 & 0.326 \\
\hline HOMA- $\beta$ & $65.9 \pm 44.3$ & $-0.38(-11.7,11.0)$ & 0.947 & $71.9 \pm 36.8$ & $-18.6(-30.4,-6.8)$ & 0.003 & 0.027 & 0.011 \\
\hline Disposition index & $0.069(0.034,0.094)$ & $0.0017(-0.05,0.013)$ & 0.534 & $0.072(0.05,0.14)$ & $-0.0087(-0.041,0.022)$ & 0.140 & 0.93 & 0.997 \\
\hline Insulinogenic index & $0.58(0.33,0.98)$ & $-0.054(-0.40,0.15)$ & 0.25 & $0.63(0.45,1.06)$ & $-0.17(-0.30,0.17)$ & 0.018 & 0.79 & 0.586 \\
\hline
\end{tabular}

Abbreviations: BMI Body mass index, FPI Fasting plasma insulin, SBP Systolic blood pressure, DBP Diastolic blood pressure, RBC Red blood cells, $P T H$ Parathyroid hormone, CPK Creatine phosphokinase, AST Aspartate aminotransferase, ALT Alanine aminotransferase, ALP Alkaline phosphatase, FPG Fasting plasma glucose, FPI Fasting plasma insulin, $2 \mathrm{~h} P C G 2 \mathrm{~h}$ post-challenge glucose, $2 \mathrm{~h} \mathrm{PCl} 2 \mathrm{~h}$ post-challenge insulin, HOMA-IR Homeostatic model of assessment - insulin resistance $\|$ Data are analyzed by paired sample t-test or Wilcoxon signed rank test where appropriate (level of significance $P \leq 0.05$ )

"Data are analyzed by independent sample t-test (level of significance $P \leq 0.05$ )

" Data are analyzed by ANCOVA using a general linear model and change values for each respective outcome with age, baseline BMI, gender and ethnicity as covariates

${ }^{a}$ Initial sample size; the sample size was reduced for some variables due to missing values

${ }^{b}$ Data are presented as mean \pm SD

' Data represented by median and inter-quartile range, Mann-Whitney U-test was used to compare median of the differences

${ }^{\mathrm{d}}$ Mean change; $95 \% \mathrm{Cl}$ or IQR where appropriate in parentheses 

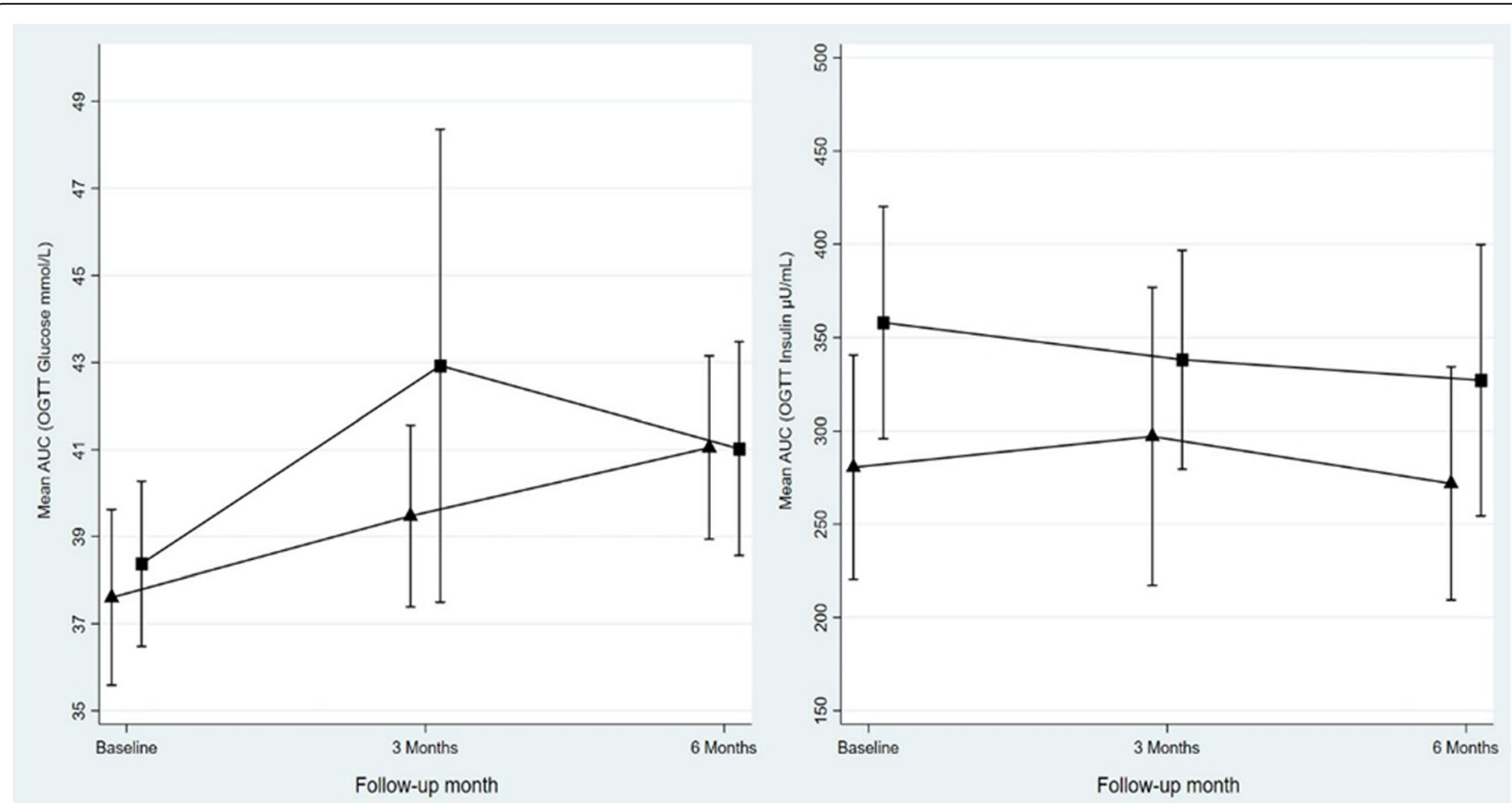

Fig. 2 Effect of vitamin D supplementation on mean area under curve (AUC) for glucose (mmol/L) and insulin $(\mu \mathrm{U} / \mathrm{mL})$ from baseline to end point for placebo (black triangles) and vitamin D (black squares) groups

recently found no effect of vitamin D supplementation on diabetes risk outcome measures, when participants received 28,000 IU of vitamin D in fortified cheese weekly [19]. Similarly, Davidson et al. observed that supplementation with high dose of vitamin D weekly $(88,865 \mathrm{IU})$ for a year did not affect glucose metabolism or insulin sensitivity but HbA1c levels were reduced in the vitamin D group [18]. Although participants were pre-diabetics they were not vitamin D-deficient, which is an essential factor to evaluate the efficacy of supplementation on glycemic measurements [27]. In another trial by Wagner et al. with short-term intervention (8 weeks) and small sample size $(n=44)$, supplementation did not affect glucose tolerance or insulin sensitivity [20]. A hyperglycemic clamp was used to calculate the disposition index (DI) in one of the trials [20] while insulin secretion was assessed by OGTT-based indices in both aforementioned studies.

Consistent to our findings were also two recent metaanalyses of RCTs [28, 29]. The first found no effect of vitamin $\mathrm{D}$ supplementation (oral or by injection) on insulin sensitivity, measured by HOMA-IR, in participants with normal glucose tolerance, pre-diabetes or type 2 diabetes [28]. Results remained unchanged when analysis was restricted to pre-diabetic participants. In the second review, where participants were only pre-diabetics, vitamin D supplementation did not alter insulin resistance but in a subgroup analysis with baseline vitamin $\mathrm{D}<50$ $\mathrm{nmol} / \mathrm{L}$, FPI and HbA1C were significantly reduced following supplementation [29].
In contrast, some studies have found a favorable effect of vitamin D intervention on glycaemic measures. In a study by von Hurst et al. 4000 IU of vitamin D daily for 6 months reduced insulin resistance and fasting insulin, in an insulin-resistant and vitamin D deficient population. Although these findings were promising, the study included only women and HOMA-IR was used as an insulin sensitivity measure, which reflects liver and not whole body insulin sensitivity [11]. In another intervention study conducted by Mitri et al., low dose, shortterm vitamin D supplementation (2000 IU daily for 16 weeks) improved $\beta$-cell function and had a marginal effect on attenuating the rise in HbA1c [30]. However, this study only adjusted for seasonal changes and lacked other important confounding factors such as age, BMI and gender. Nagpal et al. also reported an improvement in postprandial insulin sensitivity although the clinical trial included only men who were obese and non-diabetic [31]. In addition, Nikooyeh et al., demonstrated a significant reduction in fasting glucose, HbA1c and insulin resistance (HOMA-IR) when participants with Type 2 Diabetes received vitamin-D fortified yoghurt [32].

In our study, although we were able to include severely vitamin D-deficient and pre-diabetic participants in a relatively large study sample, we still could not observe any correlations between the outcomes and the increase in $25(\mathrm{OH}) \mathrm{D}$ level in the intervention group. It is worth mentioning that, although there was a substantial increase in $25(\mathrm{OH}) \mathrm{D}$ concentrations, study participants 
only achieved serum $25(\mathrm{OH})$ D levels of approximately $35 \mathrm{ng} / \mathrm{mL}$ after 6 months intervention period. This is just above the lowest level of the normal range of vitamin $\mathrm{D}$ status and it could be attributed to the absorption of the supplements in participants with high BMI [33]. Most participants in the vitamin $\mathrm{D}$ group were in the obese or overweight range $\left(\mathrm{BMI} \geq 30 \mathrm{Kg} / \mathrm{m}^{2}\right)$ and this may be associated with smaller increases in $25(\mathrm{OH})$ D concentrations following the supplementation [33]. In this case some may argue that the dose of supplementation should exceed the $4000 \mathrm{IU} /$ day, especially in extremely deficient participants. According to available evidence vitamin D supplementation dose between $4000 \mathrm{IU}$ and $10,000 \mathrm{IU}$ per day has shown no toxic effects [27, 34], however in the current study supplementation was kept to the lower adverse effect dose as more research is needed about the efficacy and safety of higher doses.

When comparing the vitamin D and placebo groups following the intervention period, a decrease was found in PTH in the vitamin D group. This is an expected observation since a reduction of parathyroid hormone has been associated with vitamin D supplementation [35]. Similarly, bilirubin levels were reduced in both groups with more pronounced reduction in the vitamin $\mathrm{D}$ group. The net effect of vitamin D supplementation is likely to be obstructed by the decreased levels of bilirubin. Animal studies have shown that bilirubin treatment in mice reduced blood glucose levels and increased insulin sensitivity [36]. Recent meta-analysis in human studies also confirm the potential protective role of bilirubin against the risk of diabetes [37].

Strengths of our study include the relatively large sample size and population characteristics. Participants were at pre-diabetic stage and most of them were severely vitamin $\mathrm{D}$ deficient. In addition, we were able to assess $\beta$-cell function by multiple measurements which has only been examined by limited number of interventional studies. The outcomes of these measurements could be attributed to our exclusively pre-diabetic population which excludes any bias introduced by mixed diabetes status study sample. In group comparison between baseline and end-point we were able to adjust for multiple confounding factors including age, baseline BMI and gender but did not adjust for seasonal changes. However, we would not expect an important effect from the seasonal change since Qatar has vast sunlight throughout the year. The study population included participants of Arab or Asian ethnicity and thus the present findings are population specific and cannot be easily extrapolated to the general population. Some may also argue that 6 months of vitamin D supplementation was not enough to observe the effect on glycemic parameters especially for participants like ours with high BMI. Compliance regarding the vitamin D intake may have introduced bias since it was self-administered. Finally, $77.2 \%$ of the participants in the vitamin D group had family history of diabetes, which could have contributed genetically in attenuating any effects of vitamin D on glycemic measures as it is well known that diabetes is highly inheritable [38].

\section{Conclusions}

According to our findings, supplementation with vitamin D did not improve insulin sensitivity, insulin secretion, or glucose tolerance in our pre-diabetic and highly vitamin $\mathrm{D}$ deficient population. Larger and multicenter intervention studies, in such populations, with longer duration are required to examine the role of vitamin $\mathrm{D}$, combined with other lifestyle interventions targeting risk factors and surrogate markers of T2DM.

\section{Supplementary information}

Supplementary information accompanies this paper at https://doi.org/10. 1186/s40795-019-0311-x

Additional file 1: Table S1. Effect of vitamin D supplementation reflected in OGTT measures overtime for the two groups.

Additional file 2: Table S2. Bivariate associations between vitamin D change and clinical characteristics from baseline to 6 months intervention in the vitamin D group.

\section{Abbreviations}

[25-(OH)D]: Vitamin D; 2 h PCG: 2 h Post-challenge glucose; 2 h PCl: 2 h Postchallenge insulin; ALP: Alkaline phosphatase; ALT: Alanine aminotransferase; AST: Aspartate aminotransferase; AUC: Area under the curve; BMI: Body mass index; CLIA: Chemiluminescence immunoassay; CMIA: Chemiluminescent Micro Particle Immunoassay; CPK: Creatine phosphokinase; DBP: Diastolic blood pressure; FINDRISC: Finnish Diabetes Risk Score; FPG: Fasting plasma glucose; FPI: Fasting plasma insulin; HMC: Hamad Medical Corporation; HOMA- $\beta$ : Homeostatic Model of Assessment- Beta; HOMA-IR: Homeostatic Model of Assessment - Insulin Resistance; HTN: Hypertension; IHD: Ischemic heart disease; OGTT: Oral glucose tolerance test; PTH: Parathyroid hormone; RBC: Red blood cells; RCTs: Randomized control trials; SBP: Systolic blood pressure; T2DM: Type 2 diabetes; ULN: Upper limit of normal

\section{Acknowledgements}

The authors would like to thank all participants, researchers, and the nursing and administrative staff at Hamad Medical Corporation for their continuous support and commitment to the project.

\section{Authors' contributions}

Conceptualization, MAT and ES; Methodology, MAT and ES; Validation, AS, $A J, K A M B$ and $A A H$; Formal Analysis, AS, BV, HA and ZSB; Investigation, AJ and KAMB; Resources, AJ and KAMB; Data Curation, ZSB, AS, KAMB and HSN; Writing - Original Draft Preparation, MAT, AS and VL; Writing - Review \& Editing, MAT, ES, AS, VL, AJ, AAH, KAMB, and HA; Visualization, MAT, AS and VL; Supervision, AS, AJ, KAMB, HSN and VL; Project Administration, AS and HSN; Funding Acquisition, MAT, ES. All authors read and approved the final manuscript.

\section{Funding}

This work was supported by NPRP No. 6-273-3-067, from the Qatar National Research Fund (a member of Qatar Foundation). The funding body was not involved in the study design; collection, analysis and interpretation of data; and in writing the manuscript. The statements made herein are solely the responsibility of the authors. 


\section{Availability of data and materials}

The datasets used and/or analysed during the current study are available from the corresponding author on reasonable request.

\section{Ethics approval and consent to participate}

This intervention study was conducted at Hamad Medical Corporation (HMC) in Doha, Qatar and the research ethics board of HMC approved the protocol. A written informed consent was obtained from all participants at enrollment.

\section{Consent for publication}

There is no identifiable information of the trial participants in the present manuscript, therefore it is not applicable.

\section{Competing interests}

The authors declare that they have no competing interests.

\section{Author details}

'Public Health Department, Ministry of Public Health, Doha, Qatar. ${ }^{2}$ Biomedical Research Department, Ministry of Public Health, P.O. Box 42, Al Khaleej Str, Al Rumaila, Doha, Qatar. ${ }^{3}$ Diabetes and Endocrine Department, Hamad Medical Corporation, Doha, Qatar. ${ }^{4}$ Qatar Diabetes Association, Qatar Foundation, Doha, Qatar.

Received: 22 May 2019 Accepted: 24 September 2019

\section{Published online: 10 October 2019}

\section{References}

1. Reid IR, Bolland MJ, Grey A. Effects of vitamin D supplements on bone mineral density: a systematic review and meta-analysis. Lancet. 2014;383: 146-55.

2. Al Mheid I, Quyyumi AA. Vitamin D and cardiovascular disease: controversy unresolved. J Am Coll Cardiol. 2017;70:89-100.

3. Tamez $\mathrm{H}$, Thadhani RI. Vitamin D and hypertension: an update and review. Curr Opin Nephrol Hypertens. 2012;21:492-9.

4. Feldman D, Krishnan AV, Swami S, Giovannucci E, Feldman BJ. The role of vitamin D in reducing cancer risk and progression. Nat Rev Cancer. 2014;14: 342-57.

5. Mitri J, Muraru MD, Pittas AG. Vitamin D and type 2 diabetes: a systematic review. Eur J Clin Nutr. 2011;65:1005-15.

6. Di Cesar DJ, Ploutz-Snyder R, Weinstock RS, Moses AM. Vitamin D deficiency is more common in type 2 than in type 1 diabetes. Diabetes Care. 2006;29:174

7. Forouhi NG, Ye Z, Rickard AP, Khaw KT, Luben R, Langenberg C, et al. Circulating 25-hydroxyvitamin D concentration and the risk of type 2 diabetes: results from the European Prospective Investigation into Cancer (EPIC)-Norfolk cohort and updated meta-analysis of prospective studies. Diabetologia. 2012;55:2173-82.

8. Song Y, Wang L, Pittas AG, Del Gobbo LC, Zhang C, Manson JE, et al. Blood 25-hydroxy vitamin $D$ levels and incident type 2 diabetes: a meta-analysis of prospective studies. Diabetes Care. 2013:36:1422-8.

9. Ogurtsova K, da Rocha Fernandes JD, Huang Y, et al. IDF diabetes atlas: global estimates for the prevalence of diabetes for 2015 and 2040. Diabetes Res Clin Pract. 2017;128:40-50.

10. Kayaniyil S, Retnakaran R, Harris SB, Vieth R, Knight JA, Gerstein HC, et al. Prospective associations of vitamin D with beta-cell function and glycemia: the PROspective Metabolism and ISlet cell Evaluation (PROMISE) cohort study. Diabetes. 2011;60:2947-53.

11. von Hurst PR, Stonehouse W, Coad J. Vitamin D supplementation reduces insulin resistance in south Asian women living in New Zealand who are insulin resistant and vitamin D deficient - a randomised, placebo-controlled trial. Br J Nutr. 2010;103:549-55.

12. Shab-Bidar S, Neyestani TR, Djazayery A, Eshraghian MR, Houshiarrad A, Kalayi A, et al. Improvement of vitamin D status resulted in amelioration of biomarkers of systemic inflammation in the subjects with type 2 diabetes. Diabetes Metab Res Rev. 2012;28:424-30.

13. Krul-Poel YH, Ter Wee MM, Lips P, Simsek S. Management of endocrine disease: the effect of vitamin D supplementation on glycaemic control in patients with type 2 diabetes mellitus: a systematic review and metaanalysis. Eur J Endocrinol. 2017;176:R1-R14.

14. Lee CJ, lyer G, Liu Y, Kalyani RR, Bamba N, Ligon CB, et al. The effect of vitamin $\mathrm{D}$ supplementation on glucose metabolism in type 2 diabetes mellitus: a systematic review and meta-analysis of intervention studies. Diabetes Complicat. 2017;31:1115-26.

15. Wu C, Qiu S, Zhu X, Li L. Vitamin D supplementation and glycemic control in type 2 diabetes patients: a systematic review and meta-analysis. Metabolism. 2017;73:67-76.

16. Mirhosseini N, Vatanparast H, Mazidi M, Kimball SM. The effect of improved serum 25-Hydroxyvitamin D status on glycemic control in diabetic patients: a meta-analysis. J Clin Endocrinol Metab. 2017;102:3097-110.

17. Li X, Liu Y, Zheng Y, Wang P, Zhang Y. The effect of vitamin D supplementation on glycemic control in type 2 diabetes patients: a systematic review and meta-analysis. Nutrients. 2018;10:375.

18. Davidson MB, Duran P, Lee ML, Friedman TC. High-dose vitamin D supplementation in people with prediabetes and hypovitaminosis D. Diabetes Care. 2013;36:260-6.

19. Moreira-Lucas TS, Duncan AM, Rabasa-Lhoret R, Vieth R, Gibbs AL, Badawi A et al. Effect of vitamin D supplementation on oral glucose tolerance in individuals with low vitamin D status and increased risk for developing type 2 diabetes (EVIDENCE): a double-blind, randomized, placebo-controlled clinical trial. Diabetes Obes Metab. 2017:19:133-41.

20. Wagner H, Alvarsson M, Mannheimer B, Degerblad M, Ostenson CG. No effect of high-dose vitamin $D$ treatment on beta-cell function, insulin sensitivity, or glucose homeostasis in subjects with abnormal glucose tolerance: a randomized clinical trial. Diabetes Care. 2016:39:345-52.

21. Rajan S, Weishaar T, Keller B. Weight and skin colour as predictors of vitamin D status: results of an epidemiological investigation using nationally representative data. Public Health Nutr. 2017;20:1857-64.

22. Word Health Organization. Use of glycated haemoglobin ( $\mathrm{HbA1c}$ ) in the diagnosis of diabetes mellitus: abbreviated report of a WHO consultation. Geneva: World Health Organization; 2011.

23. Alberti G, Zimmet $P$, Shaw J. Metabolic syndrome--a new world-wide definition. A Consensus Statement from the International Diabetes Federation. Diabet Med. 2006:23:469-80.

24. Lindstrom J, Tuomilehto J. The diabetes risk score: a practical tool to predict type 2 diabetes risk. Diabetes Care. 2003:26:725-31.

25. Matthews DR, Hosker JP, Rudenski AS, Naylor BA, Treacher DF, Turner RC. Homeostasis model assessment: insulin resistance and beta-cell function from fasting plasma glucose and insulin concentrations in man. Diabetologia. 1985:28:412-9.

26. Matsuda M, DeFronzo RA. Insulin sensitivity indices obtained from oral glucose tolerance testing: comparison with the euglycemic insulin clamp. Diabetes Care. 1999;22:1462-70.

27. Vieth $R$, Chan PC, MacFarlane GD. Efficacy and safety of vitamin D3 intake exceeding the lowest observed adverse effect level. Am J Clin Nutr. 2001;73:288-94

28. Seida JC, Mitri J, Colmers IN, Majumdar SR, Davidson MB, Edwards AL, et al. Clinical review: effect of vitamin D3 supplementation on improving glucose homeostasis and preventing diabetes: a systematic review and metaanalysis. J Clin Endocrinol Metab. 2014;99:3551-60

29. Poolsup N, Suksomboon N, Plordplong N. Effect of vitamin D supplementation on insulin resistance and glycaemic control in prediabetes: a systematic review and meta-analysis. Diabet Med. 2016;33(3):290-9.

30. Mitri J, Dawson-Hughes B, Hu FB, Pittas AG. Effects of vitamin D and calcium supplementation on pancreatic beta cell function, insulin sensitivity, and glycemia in adults at high risk of diabetes: the calcium and vitamin D for diabetes mellitus (CaDDM) randomized controlled trial. Am J Clin Nutr. 2011:94:486-94

31. Nagpal J, Pande JN, Bhartia A. A double-blind, randomized, placebocontrolled trial of the short-term effect of vitamin D3 supplementation on insulin sensitivity in apparently healthy, middle-aged, centrally obese men. Diabet Med. 2009;26:19-27.

32. Nikooyeh B, Neyestani TR, Farvid M, Alavi-Majd H, Houshiarrad A, et al. Daily consumption of vitamin D- or vitamin D + calcium-fortified yogurt drink improved glycemic control in patients with type 2 diabetes: a randomized clinical trial. Am J Clin Nutr. 2011:93:764-71.

33. Mazahery $H$, von Hurst PR. Factors affecting 25 -Hydroxyvitamin D concentration in response to vitamin D supplementation. Nutrients. 2015;7:5111-42.

34. Heaney RP, Davies KM, Chen TC, Holick MF, Barger-Lux MJ. Human serum 25-hydroxycholecalciferol response to extended oral dosing with cholecalciferol. Am J Clin Nutr. 2003;77:204-10.

35. Lotito A, Teramoto M, Cheung M, Becker K, Sukumar D. Serum parathyroid hormone responses to vitamin $D$ supplementation in overweight/obese 
adults: a systematic review and meta-analysis of randomized clinical trials. Nutrients. 2017;9:241.

36. Liu J, Dong H, Zhang Y, Cao M, Song L, Pan Q, et al. Bilirubin increases insulin sensitivity by regulating cholesterol metabolism, adipokines and PPARgamma levels. Sci Rep. 2015;5:9886.

37. Zhu B, Wu X, Bi Y, Yang Y. Effect of bilirubin concentration on the risk of diabetic complications: a meta-analysis of epidemiologic studies. Sci Rep. 2017;7:41681.

38. Florez JC, Hirschhorn J, Altshuler D. The inherited basis of diabetes mellitus: implications for the genetic analysis of complex traits. Ann Rev Genom Hum Genet. 2003:4:257-91.

\section{Publisher's Note}

Springer Nature remains neutral with regard to jurisdictional claims in published maps and institutional affiliations.

Ready to submit your research? Choose BMC and benefit from:

- fast, convenient online submission

- thorough peer review by experienced researchers in your field

- rapid publication on acceptance

- support for research data, including large and complex data types

- gold Open Access which fosters wider collaboration and increased citations

- maximum visibility for your research: over $100 \mathrm{M}$ website views per year

At BMC, research is always in progress.

Learn more biomedcentral.com/submissions 